\title{
Design and development of high voltage capacitor voltage drop device
}

\author{
Renzhen Feng, Yangwan Li,Gao wei \\ State grid changji electric power sypply company of Wulumuqi Province \\ Xinjiang, China \\ Jun21138303@qq.com,zym_ym_xj@163.com,413855933@qq.com
}

\begin{abstract}
With the development of computer technology and electronic technology information, more and more monitoring means for power transmission lines are used. Many domestic companies have developed a variety of equipment for monitoring the operation of transmission lines. However, the power supply problem of these equipment has not been effectively solved so far. This paper designs a high voltage withstanding capacitor and voltage transformer device, which can obtain the energy of the transmission line without affecting the quality of the power supply on the transmission line. Through voltage transformation, it can supply power for the monitoring equipment on the transmission line. Through experiment and field operation, it can provide running electricity for the high-power monitoring camera. The source has achieved good results.
\end{abstract}

Keywords-High voltage capacitor. Voltage transformer. Voltage sharing capacitor

\section{INTRODUCTION}

With the rapid development of computer and microelectronics technology, there are more and more monitoring means for substation equipment, transmission lines, tower equipment and so on. At the same time, the monitoring equipment produced has been used more and more widely. However, in the monitoring of transmission lines, due to the limitations of working environment and installation location, AC power supply can not be used. The current solutions include solar battery power supply, coil online power supply, etc. The coil on-line power supply is limited by its volume and installation convenience, so the power obtained is relatively small, and when the number of coil turns is increased, it will have an impact on the power supply of the transmission line. Therefore, from 2016 onwards, the power grid will no longer promote the installation of coil power equipment on-line. The way of solar power supply is mainly affected by the weather, and the climate difference between the north and the South also makes it difficult to popularize. The cost is also one of the reasons that affect the rapid popularization of this way of power supply. Therefore, the development of a high efficiency, low cost, does not affect the stability of the transmission line power collection device is of great value and economic value. In this paper, a kind of equipment is designed to provide stable power supply for monitoring system or equipment by means of capacitor step-down, voltage transformer conversion and power signal processing. Through high-speed power switching circuit, almost no impact on the transmission signal of the grid, and provide effective power supply for the corresponding electrical equipment.

\section{The SURVIVABILITY AsSOCIATION MODEL OF LARGE- SCALE NETWORK}

\section{A. The working principle}

The working principle of capacitor charging is to add a thermal explosive disconnector by connecting the high voltage capacitor in parallel with the insulator to prevent the high voltage capacitor from breaking down the short circuit.The connection is shown in the following figure:

High voltage transmission line

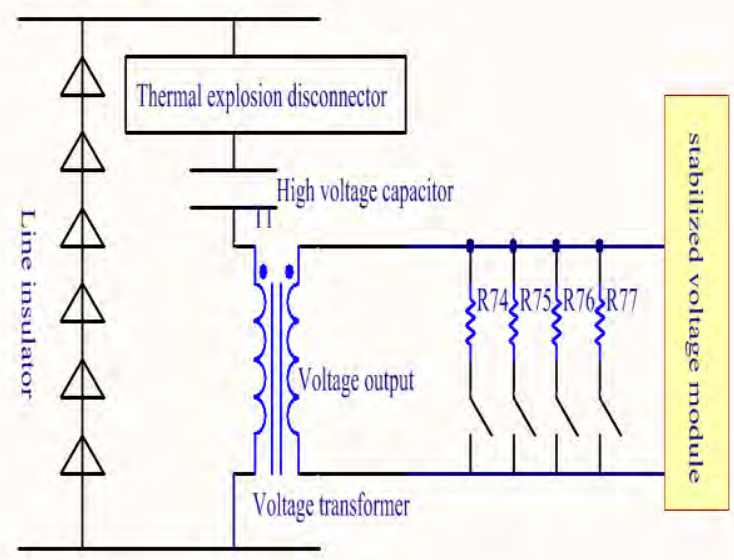

Fig. 1 block diagram of power receiving device

The conventional method of converting high voltage alternating current into low voltage direct current is to use transformer buck and then rectifier filter. When the size and cost of the acceptor are limited, the simplest and practical method is to use capacitive buck power supply.

There are the following problems when using capacitance to depressurization:

(1) Choose the appropriate capacitor according to the current of the load and the working frequency of the AC, not the voltage and power of the load.

(2) High voltage capacitors must be composed of nonpolar capacitors and cylindrical thin film capacitors with DC withstand voltage of tens of kilovolts in series. The power frequency withstand voltage (converted to DC withstand 
voltage) of capacitors in series can meet the requirements of line insulation coordination.

(3) capacitor depressurization is not suitable for dynamic load conditions.

In order to stabilize the load and improve the stability of the system, the matching power output is dynamically adjusted according to the power transformation of the load.

\section{B. Design of electricity collection device}

The capacitor is suspended on $110 \mathrm{kV}$ overhead lines and connected in parallel with line insulators. According to the corresponding standards, the maximum power frequency voltage is $127 \mathrm{kV}$ under normal conditions. High voltage capacitors must be able to pass DC, power frequency and lightning impulse tests. The discharge voltage of $110 \mathrm{kV}$ line insulator $50 \%$ is $700 \mathrm{kv}$. So the film capacitor with DC withstand voltage of $80 \mathrm{kV}$ is chosen. Its length is $100 \mathrm{~mm}$ and diameter is $50 \mathrm{~mm}$. Ten series capacitors are molded by silicone rubber.

Cylindrical film capacitors are equivalent to plate capacitors.

$$
C=A * S / d
$$

In the formula, $\mathrm{C}$ is the electric capacity (farad), $\mathrm{S}$ is the area (square meter) of the plate, $\mathrm{D}$ is the distance (meter) between the plates, and $\mathrm{A}$ is the coefficient of material characteristics. $\mathrm{N}$ series capacitors in series, equivalent to $\mathrm{D}$ increase by $\mathrm{N}$.

$$
C_{\mathrm{T}}=C / N=A * S / N * d
$$

Formula (2): multiply $\mathrm{N} * \mathrm{~d}$ above and below the scale symbol so that $\mathrm{D}=\mathrm{N} * \mathrm{~d}$ (the total length of the gap) and bring $\mathrm{U} 50 \%=\mathrm{k} * \mathrm{D}$ (in a uniform electric field $\mathrm{U} 50 \%$ is proportional to the gap distance D. For simplicity, assume that the voltage on each capacitor in series is equal).

$$
C=A \frac{S d N}{(N d)^{2}}=\frac{A}{k^{2}} \frac{V}{\left(U_{50 \%}\right)^{2}}=B \frac{V}{\left(U_{50 \%}\right)^{2}}
$$

Formula (3): $\mathrm{V}$ is the total volume of series capacitor, and $\mathrm{U} 50 \%$ is the $50 \%$ discharge voltage of series capacitor. It can be seen that the capacitance of series capacitor is directly proportional to the total volume after series connection, inversely proportional to the square of withstand voltage value, independent of the number of series connection. The capacitance of the high voltage capacitor can be obtained by introducing the parameters into the above formula. $C=597 p F$

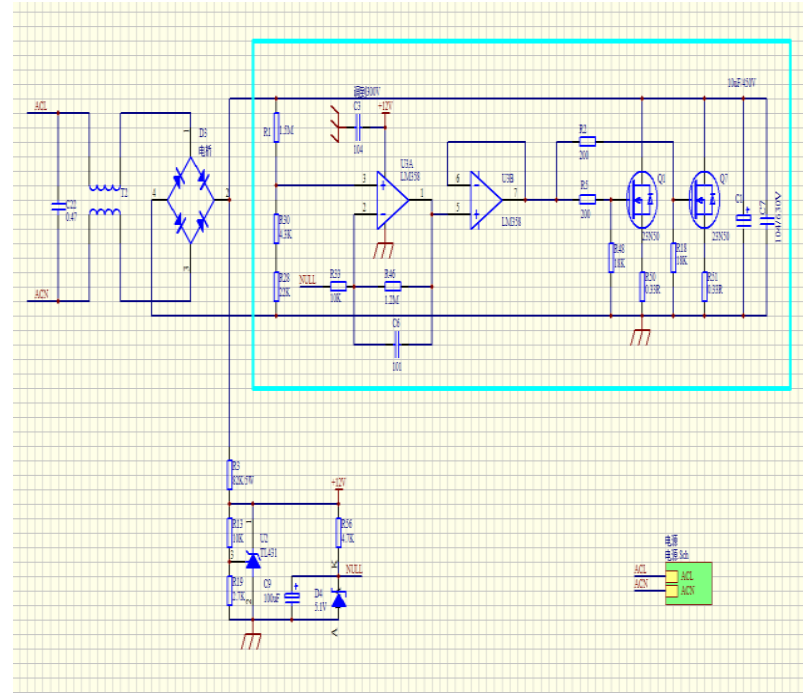

Fig. 2 Voltage stabilizing circuit

The voltage stabilizing module of the electricity collecting device is shown in Figure 2. The traditional voltage stabilizing circuit is composed of power transformer, rectifier circuit and filter circuit.

The parallel electronic voltage stabilizing circuit adopts cascaded input terminals and output terminals in parallel. The AC voltage of series output of high voltage line capacitor and voltage transformer is inputted into the rectifier circuit made up of bridge rectifier structure. The rectifier circuit outputs pulsating DC voltage. The pulsating DC voltage passes through the filter circuit made up of reactor elements. The filtering principle is that the parallel capacitor is connected in the circuit and the output of the filter circuit fluctuates. The output voltage is stabilized by two 23N50 MOSFET transistors in parallel, and the driving circuit of the MOSFET transistor is designed.

In Fig.2, CON2 is about 7-30V AC (secondary output voltage of voltage transformer), $\mathrm{C} 22$ and $\mathrm{T} 2$ are filtered, and the $\mathrm{AC}$ voltage is converted to $\mathrm{DC}$ voltage after the bridge rectifier circuit.

$$
V_{T G}=(7 \sim 30) \sqrt{2} \approx 9.9 \sim 42.4 \mathrm{~V}
$$

Choose the appropriate voltage divider resistance, use R1, $\mathrm{R} 30$ and R28 resistors in series to divide voltage, take the voltage of the first node as the input voltage of LM358 voltage comparator, so that the voltage of the first node is:

$$
V_{1}=V_{T G} \cdot \frac{R_{28}+R_{30}}{R_{28}+R_{30}+R_{1}} \approx 5.1 \mathrm{~V}
$$

The NULL terminal voltage is stabilized at $5.1 \mathrm{~V}$ by a $5.1 \mathrm{~V}$ voltage regulator series resistance, and the LM358 voltage comparator outputs a voltage input voltage follower with positive and negative polarities. The voltage follower acts as isolation. The same polarity voltage at the 7 terminals provides driving voltage for the parallel MOSFET, R5 and R6 are driving resistors, and $\mathrm{R} 48$ releases the MOSFET gate. The extreme residual voltage prevents MOSFET tube misleading.

$\mathrm{C} 1$ is an electrolytic capacitor for low frequency filtering and compensation; $\mathrm{C} 7$ is an ordinary capacitor for eliminating high frequency and clutter. V1 and VNULL are compared by a 
voltage comparator. The voltage of V1 varies according to the change of the front-end circuit. It is very unstable, but it fluctuates around $5.1 \mathrm{~V}$. This will cause the positive and negative polarity of the 7-terminal output signal to change back and forth. If the increase of the front-end voltage causes the voltage of $\mathrm{V} 1$ to be greater than $5.1 \mathrm{~V}$, the output polarity will be positive. Voltage, under the action of this voltage MOS transistor turn on, using the MOS switch to stabilize the leakage extreme voltage, the voltage will be controlled in a small range of $310 \mathrm{~V}$ fluctuations, and vice versa.

The power supply protection includes overvoltage protection and overcurrent protection. When the high-voltage line fault and lightning impulse produce surge current, which will lead to insufficient output power of the subsequent circuit, can not guarantee the normal operation of the detection equipment. Estimation of the maximum inrush current: If the maximum lightning voltage or internal overvoltage is $700 \mathrm{kV}$ and the equivalent frequency is about $1 \mathrm{MHz}$, the maximum inrush current is obtained. During overvoltage, the inductor raises the voltages of $\mathrm{ACA}$ and $\mathrm{ACB}$, causing the varistor to act, and most of the surge current flows through the varistor. When suffering from lightning impulse, the high frequency of lightning wave causes short circuit of high voltage capacitor, which is equivalent to lightning wave acting directly on voltage transformer. This is absolutely necessary. In this design, $10 \mathrm{kV}$ lightning arrester and air gap are connected in parallel on the primary side of the voltage transformer, which can double guarantee the damage caused by lightning impulse to the electrical equipment.

\section{CONCLUSIONS}

In order to test the voltage stabilizing effect of the voltage stabilizing circuit and the limiting effect on the voltage of the primary side of the voltage transformer, the voltage of the primary side and the secondary side of the voltage transformer are recorded when the power frequency voltage rises. The stable operating phase voltage of the $110 \mathrm{kV}$ line is $63.5 \mathrm{kV}$ and the maximum overvoltage is $127 \mathrm{kv}$, so the power frequency voltage is increased to $127 \mathrm{kv}$. The operation of the whole unit under steady state is observed. The test is shown in Table 1. Table 1: U1 is the power frequency applied voltage, $\mathrm{U} 2$ is the primary voltage of the voltage transformer, $\mathrm{U} 3$ is the secondary voltage of the voltage transformer.

\begin{tabular}{|c|c|c|c|c|c|}
\hline $\mathrm{U} 1 / \mathrm{kV}$ & $\mathrm{U} 2 / \mathrm{kV}$ & $\mathrm{U} 3 / \mathrm{V}$ & $\mathrm{U} 1 / \mathrm{kV}$ & $\mathrm{U} 2 / \mathrm{kV}$ & $\mathrm{U} 3 / \mathrm{V}$ \\
\hline 4.9 & 1.52 & 33.4 & 55.6 & 8.43 & 182.6 \\
\hline 10.6 & 2.13 & 46.3 & 60.7 & 9.14 & 197.4 \\
\hline 14.9 & 2.71 & 59.5 & 63.8 & 9.82 & 216.3 \\
\hline 19.0 & 3.54 & 77.4 & 70.4 & 10.05 & 220.2 \\
\hline 25.7 & 4.26 & 91.3 & 73.5 & 10.06 & 219.4 \\
\hline 30.5 & 4.95 & 107.5 & 80.7 & 10.06 & 220.5 \\
\hline 35.8 & 5.63 & 121.5 & 91.3 & 10.07 & 220.6 \\
\hline 40.2 & 6.44 & 140.3 & 102.8 & 9.99 & 219.3 \\
\hline 46.8 & 7.06 & 153.2 & 113.9 & 10.08 & 221.5 \\
\hline 50.4 & 7.75 & 168.4 & 126.3 & 10.04 & 220.3 \\
\hline
\end{tabular}

Fig. 3 Output voltage chart
In order to analyze the effect of voltage stabilization more intuitively, the following diagram is a graph of power frequency applied voltage and transformer primary voltage.

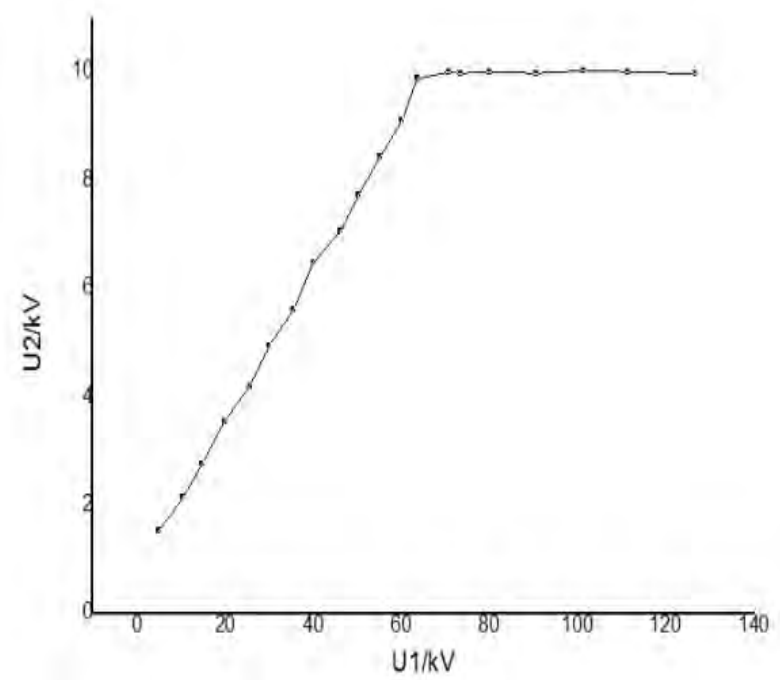

Fig.4 Relationship of frequency voltage and transformer primary side voltage

As can be seen from the above diagram, when the voltage is applied, the primary voltage of the transformer increases linearly. When the power frequency voltage is added to about $60 \mathrm{kv}$, the primary voltage of the transformer has basically reached the rated voltage of $10 \mathrm{kV}$, then the power frequency voltage is increased to $63.5 \mathrm{kV}$, and finally to 127 $\mathrm{kV}$. The voltage keeps fluctuating in a very small range around $10 \mathrm{kV}$. This shows that (1) the device can operate well in a short time under overvoltage, (2) the voltage of the secondary side of the voltage transformer is stabilized at $220 \mathrm{~V}$ in the voltage stabilization circuit, and the voltage of the primary side is controlled at $10 \mathrm{kV}$ according to the ratio relationship, and the voltage stabilization effect is good.

\section{CONCLUSIONS}

In this paper, the design of high voltage capacitor and voltage drop power supply is presented, and the power supply system based on this method is completed. The test results show that the system is stable and reliable, and can provide stable and effective power support for most high-voltage side measuring equipment.

\section{REFERENCES}

[1] [1] ZHAO li-hua, GAO Jin-qiang. Discussion on intelligent electric power equipment[J]. High Voltage Apparatus, 2010 , 46(12):1-4.

[2] [2] XIONG Lan, LIU Yu. Ultraviolet on-line monitoring system for contaminated insulators $[\mathrm{J}]$. Transaction of China Electrotechnical Society, $2010,25(7): 186-191$.

[3] [3] LIU Ya-Dong, SHENG Ge-hao. Current Transformer Draw-out Power Supply Design Based on Phase Angle Control Method[J]. Automation of Eletric Power Systems. 2011,35 (19) : 72-76

[4] [4] ZANGL H,BRETTERKLIEBER T,BRASSEUR G. Energyharvesting for online condition monitoring of high voltageoverhead power line. Proceedings of 2008 IEEEInternational Instrumentation and Measurement TechnologyConference . 2008 
[5] [5] LI Xian-zhi, DU Lin. A novel scheme of draw-out power supply utilized in transmission line state monitoring $[\mathrm{J}]$. Automation of Electric Power Systems, 2008,32(1):76-80

[6] [6] QIAN Zheng. Power supply for high voltage circuit of active electronic current transformer[J]. High Voltage Engineering, 2004,40 (2) : 135-138
[7] [7] P.R.Wilson, J.N.Ross, A.D.Brown. Optimizing the Jiles-Atherton Model of Hysteresis by Genetic Algorithm[J]. IEEE Transactions on Magnetics. 2011,37(2):989-993 